\title{
Medicamentos Não Sujeitos a Receita Médica: Compatibilizando Acesso e Segurança
}

\section{Pharmacy Medicines not Subject to Medical Prescription: Compatible Access and Security}

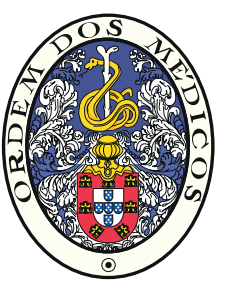

\author{
Ema PAULINO $\triangle^{1}$ \\ Acta Med Port 2016 Sep;29(9):495-496 - http://dx.doi.org/10.20344/amp.8231
}

Palavras-chave: Automedicação; Medicamentos Não Sujeitos a Receita Médica; Portugal; Segurança; Serviços de Farmácia Comunitária.

Keywords: Community Pharmacy Services; Nonprescription Drugs; Portugal; Safety; Self Medication.

É inegável a importância que a adoção de comportamentos saudáveis pode desempenhar (e desempenha já hoje em dia) na prevenção da doença e das suas complicações. A bem da sustentabilidade dos sistemas de saúde, é imperioso atrasar o aparecimento das doenças crónicas, identificá-las o mais precocemente possível quando presentes, e prevenir complicações secundárias após o diagnóstico médico.

De igual forma, saber o que fazer quando se é confrontado com problemas de saúde 'menores', muitas vezes autolimitados ou passíveis de serem resolvidos através da utilização de medicamentos não sujeitos a receita médica, permite evitar idas ao médico desnecessárias, promovendo desta forma uma maior eficiência na utilização dos recursos disponíveis, ao mesmo tempo que melhora os resultados em saúde, a conveniência do cidadão, e a sua qualidade de vida. ${ }^{1}$ Por exemplo, nos Estados Unidos da América, estima-se que cada dólar gasto em medicamentos não sujeitos a receita médica gera uma poupança correspondente de seis a sete dólares. ${ }^{2}$

Com vista a capacitar o cidadão para este papel cada vez mais central na gestão da sua própria saúde, campanhas de informação e educação podem ser úteis, mas não são suficientes. O conceito de autocuidados, que tem vindo a ganhar relevância neste domínio, exige uma estratégia integrada, envolvendo os contextos escolares e laborais, e que seja aplicada desde a mais tenra idade. Efetivamente, o cidadão interage com outras estruturas, desde a escola ao meio familiar, muito mais frequente e precocemente do que com as estruturas de saúde. E é no conjunto destes meios que define os seus comportamentos atuais e futuros, e que adquire as competências cognitivas e a capacidade de compreender e usar a informação disponível, de forma a promover e manter a sua boa saúde. Esta é, aliás, a definição de literacia em saúde da Organização Mundial da Saúde (OMS).

Contudo, esta capacitação do cidadão não invalida que vá sempre continuar a existir uma assimetria de informação entre este, e os profissionais de saúde que foram formados com o intuito específico de o cuidar. Independentemente das competências que o cidadão vá adquirindo, baseadas inclusivamente na sua própria experiência e vivência pessoal, o profissional de saúde terá inevitavelmente acesso a informação, assim como a capacidade de a processar e utilizar, que o colocam numa situação privilegiada.

Os profissionais de saúde, nomeadamente os farmacêuticos, sabem e reconhecem que sintomas como a tosse, comum em doenças autolimitadas como as constipações, pode ser afinal um efeito adverso de um medicamento para a hipertensão, ou o primeiro sinal de uma doença respiratória crónica não diagnosticada, requerendo, portanto, referenciação ao médico.

Do ponto de vista do cidadão, um inquérito efetuado em 2013 pela European Platform for Patients' Organisations, Science and Industry (EPPOSI) revelou que apesar de que $90 \%$ dos inquiridos encaravam o autocuidado como uma parte vital da gestão de afeções menores e prevenção de doenças crónicas, menos de $20 \%$ se sentiam confiantes para gerir a sua própria saúde. ${ }^{3}$

É neste enquadramento que a regulamentação aplicada aos medicamentos, e nomeadamente a classificação dos mesmos em relação à necessidade ou não de apresentação de receita médica, se insere e justifica. E, dentro dos que não necessitam de receita médica, quais devem ser alvo de uma avaliação farmacêutica prévia, estando por isso circunscritos a ser dispensados na farmácia.

O artigo 'Medicamentos Não Sujeitos a Receita Médica de Dispensa Exclusiva em Farmácia em Portugal: Uma Oportunidade de Acesso Sub-Aproveitada?', de Ana Paula Martins e colegas, ${ }^{4}$ explora esta temática, contextualizando as necessidades em saúde dos cidadãos portugueses, e revendo as práticas internacionais sobre esta matéria.

São tópicos-chave neste artigo o Acesso, e a Segurança. Subliminarmente, também o é a Multidisciplinaridade, tendo em conta a relevância do contributo dos outros profissionais de saúde, e especificamente do médico, para um uso responsável dos medicamentos não sujeitos a receita médica, como referido nas respetivas conclusões.

À luz da experiência internacional, através da análise dos medicamentos classificados como medicamentos não

1. Ordem dos Farmacêuticos. Lisboa. Portugal.

$\triangle$ Autor correspondente: Ema Paulino. ema.paulino@ordemfarmaceuticos.pt

Recebido: 20 de setembro de 2016 - Aceite: 20 de setembro de 2016 | Copyright @ Ordem dos Médicos 2016 
sujeitos a receita médica de dispensa exclusiva em farmácia em sete países europeus, o estudo propõe uma lista preliminar dos medicamentos que reúnem características que justificariam a sua classificação equivalente em Portugal. E apesar de o artigo apresentar como principal limitação o facto de apenas ter considerado um painel de 7 países europeus, um inquérito efetuado em 2015 pela Federação Internacional Farmacêutica (FIP), Trends in the Regulation of Pharmacy and Access to Medicines, já relevava o aumento da existência da denominada 'terceira lista de medicamentos'. ${ }^{5}$ Este estudo revelou que em 20 dos 71 países estudados $(28,2 \%)$, os medicamentos não sujeitos a receita médica continuam a ser dispensados exclusivamente em farmácias comunitárias, mas que nos restantes 51 países, $23(45,1 \%)$ possuem uma lista de medicamentos não sujeitos a receita médica de dispensa exclusiva em farmácia, tendo este número vindo a aumentar.

Uma consideração importante é a de que em Portugal, a criação desta lista surge já alguns anos após a liberalização da venda de medicamentos não sujeitos a receita médica. O que, inevitavelmente, significa que medicamentos que deveriam, por uma questão de segurança, fazer parte dessa mesma lista, estão hoje a ser dispensados sem qualquer intervenção profissional. Estando previsto o mecanismo para reavaliar a atualidade das diferentes listas de medicamentos, faz sentido que essa reavaliação seja feita no sentido de determinar quais os medicamentos que, independentemente da pertinência do reforço da educação ao cidadão para uma utilização responsável do medicamento, devem voltar a ser apenas dispensados em farmácia ou ser alvo de redimensionamento das suas embalagens, à

\section{REFERÊNCIAS}

1. GAP Taskforce on Self Care. Towards responsible self care: the role of health literacy, pharmacy and non-prescription medicines. Strawberry Hill: Global Access Partners Pty Ltd:2015.

2. American Pharmacists Association. Practice insights - pharmacists as self-care advisors. Washington: American Pharmacists Association; 2015.

3. Epposi. The Epposi barometer: consumer perceptions of self care in Europe - quantitative study 2013. Brussels: Epposi; 2013.

4. Martins AP, Gonçalves E, Marcelo A, Vilão S, Silva JA. Medicamentos não sujeitos a receita médica de dispensa exclusiva em farmácia em luz da experiência nacional e internacional. Por exemplo, na Suécia, devido a razões de segurança, a dispensa de paracetamol foi novamente restrita às farmácias, e no Reino Unido, as embalagens foram redimensionadas devido ao aumento do número de suicídios utilizando esta mesma substância.

Os farmacêuticos devem, nesta perspetiva, encarar cada dispensa de medicamentos não sujeitos a receita médica como uma oportunidade de intervenção, em linha com o preconizado no documento conjunto entre a FIP e a OMS, Joint FIP/WHO guidelines on good pharmacy practice: standards for quality of pharmacy services. ${ }^{6}$ Neste documento, o objetivo da prática farmacêutica foi definido como 'contribuir para a melhoria da saúde e ajudar doentes com problemas de saúde a tirar o maior partido dos seus medicamentos', sublinhando a sua responsabilidade acrescida face à assimetria de informação existente.

Os medicamentos não sujeitos a receita médica de dispensa exclusiva em farmácia têm ainda o potencial de reforçar a articulação dos cuidados médicos e farmacêuticos, proporcionando soluções de saúde centradas no cidadão, complementares, e geradoras de resultados em saúde. A partilha de dados entre os dois profissionais, nomeadamente através da Plataforma de Dados em Saúde, permitirá a ambos ter uma visão integrada da terapêutica, reforçando a segurança do cidadão.

Estudos como o agora publicado por Ana Paula Martins e colegas permitem aos decisores políticos e profissionais de saúde tomar decisões informadas sobre esta temática, aumentando assim o potencial de melhoria do processo de cuidados de saúde ao cidadão.

Portugal: uma oportunidade de acesso sub-aproveitada? Acta Med Port. 2016;29:542-548.

5. International Pharmaceutical Federation. Global trends shaping pharmacy - regulatory frameworks, distribution of medicines and professional services. The Hague: International Pharmaceutical Federation; 2015

6. International Pharmaceutical Federation and World Health Organization. Joint FIP/WHO guidelines on good pharmacy practice: standards for quality of pharmacy services. Geneva: International Pharmaceutical Federation and World Health Organization; 2011. 